\title{
A Digital Africa Kiswahili Holds the Key
}

\author{
Stephen Njihia Kamau
}

\begin{abstract}
1.0 Introduction
With today's increased use of Information and Communication Technologies (ICT), the world has been turned into a global village courtesy of the easy and fast means of communication over vast geographical distances (Katembo 2005). However, not all the regions in the world are included in the 'global village'. Most developing countries especially in Africa are yet to make a mark in the ICT domain. Due to this fact there exists a digital divide between the developed and the developing nations of the world.
\end{abstract}

In Africa, there are various reasons that have been advanced for the existence of the digital divide some of which have been highlighted in this article. However, much of our discussion is centered on trying to show how dependency on foreign languages such as English, French and German in spreading ICT in Africa have hindered faster digitalization of the continent. We have tried to argue for the use of local African languages in Africa as a vehicle of spreading ICT. This has been done by showing how Kiswahili, an indigenous African language and a linguistic gateway into Africa (Katembo 2005), have been utilized in an attempt to break down the foreign language barriers that highly contribute to there being a digital divide between Africa and the developed world in terms of ICT spread and usage.

\subsection{What is a digital divide?}

Vedantham (1995) as quoted by Hoffman and Novak (2000) describe the digital divide as the disparities that exist in the levels of access to information technologies between rich and poor and between suburban and inner - city residents. The Internet World Stats (2005) says that the digital divide or the digital split is a social issue referring to the differing amounts of information between those who have access to the internet and those who do not.

Simply put, the digital divide is the wide division between those who have access to Information and Communication Technologies (ICT) and are using it effectively, and those who do not (bridges.org 2004). They continue to argue that since ICT are increasingly becoming a foundation of our societies and economies, the digital divide means that the information 'have nots' are denied the option to participate in new ICT jobs, in e - governments, in ICT - improved healthcare and in ICT - enhanced education. Therefore a digital divide is a social-political problem that became an issue among concerned parties such as scholars, policy makers, and advocacy groups in the late 1990s.

In short therefore, digital divide can be said to be the social economic difference between communities in their access to computers and the internet.

Previously, the world seemed to be quite big but today, thanks to the ICT , the world has been reduced into a global village. This is because ICT, which are highly computer dependent, have created a fast means of information flow the world over (Katembo 2005). However, most of the developing countries especially in Africa are yet to be part and parcel of the global village. This is due to the fact that most of these developing countries are yet to fully embrace ICT. 
In fact, most of the developing counties are to a large extent lagging behind in the ICT sector. As bridges.org (2004) puts it, more often than not, the information 'have nots' are in the developing countries and in disadvantaged groups within countries.

As such, the developing countries are losing out a lot in terms of information access which is key to their general development. According to the bridges.org (2004), the digital divide is thus a lost opportunity - the opportunity for the information 'have nots' to use ICT to improve their lives.

\subsection{Reasons for Digital Divide in Africa}

There are several reasons given as to why Africa still lags behind in the ICT sector. They include:-

- The high cost of computers in most developing countries which means that most people have no access to personal computers. Again, the cost of accessing the internet is beyond the reach of most people in Africa and other developing countries.

- There is lack of electric power, especially in rural Africa and therefore computers cannot be used in such regions.

- Most of the African population lacks computer literacy. Also, a good percentage of people here do not know how to read and write which therefore becomes a stumbling block to acquiring computer literacy.

- Lack of telephone line in most parts of African countries, again mostly in the rural areas deny most people access to the internet which is dependent on the telephone lines for transmission.

- Foreign language dependency is also another hindrance for most Africans in their bid to utilize ICT hence the need to shift top local languages which are easily understood.

\subsection{Using Local Languages to Bridge the Digital Divide in Africa}

According to Mohochi (2002), the spread and use of computer technology, which is the heart of ICT, is language dependent. This means that this technology reaches its consumers through the language medium. The current situation in most African countries is that ICT are spread and consumed through the major world languages. This is due to the fact that this technology originates from the developed world.

Given this situation, most African countries acquire ICT through foreign languages that are not understood by a large percentage of the population. Such people are thus automatically shut out of the ICT domain. There is, therefore, a great need for Africa to start utilizing its local languages in the spread and use of ICT. This will ensure that people who do not understand foreign languages get to benefit from ICT like their counterparts in the developed countries. This way, the digital divide will have been reduced considerably. It's against this background that efforts have started being made of trying to bridge the digital divide in Africa local languages.

\subsection{The Case for Kiswahili.}

In Africa, two re-known international computer software developers namely Microsoft and Linux have started the localization of their software using Kiswahili language in a bid to bringing ICT access closer to most Africans especially in the East and Central African region. Other efforts of using Kiswahili to spread ICT in Africa include the Kiswahili text to speech (TTS) program, Kiswahili googles search engine and the Kiswahili email project. Kiswahili 
is, therefore, the first African language in the whole of Africa to be used in the computers. The main goal of the various Kiswahili localization efforts is on the one hand to bridge the digital divide between Africa and the developed world and on the other hand to expand their markets in Africa.

\subsubsection{Why Kiswahili ?}

The choice of Kiswahili by software developers as the first localization language in Africa was influenced by various reasons. These reasons include:-

a) The fact that Kiswahili has already carved itself a place in institutions of higher learning all over the world more than any other African language (Ryanga 2002). Kiswahili is a lingua franca for East Africa since the $19^{\text {th }}$ century and has now gained recognition beyond its traditional confines with a wide spread in Africa and gaining popularity and support in America, Europe and the Far East where it is taught in a number of universities. It is therefore the most indigenous language that Africa has for spreading ICT and thus can help in narrowing the digital divide.

b) Kiswahili is an easy language to learn since it is phonetic with less spelling and pronounciation complications (Mwaro 2002, Mucemi et al.2004, Katembo 2005). According to Mwaro (2002), Kiswahili's ability to assimilate and incorporate linguistic mechanisms words from other languages endears it to other language groups and makes it an easy language to be learnt by members from any of the major language classification in Africa. For example, as Amatubi (2002) explains, most visitors from European countries get to learn Kiswahili within their first year of stay in Kenya like in the case of missionaries and colonial rulers.

c) It is also a language that handles new technologies with much ease through coining of new terminologies (Mazrui and Mazrui 1995, Katembo 2005). Already, efforts have been made by some universities in Europe and America of preparing Kiswahili for computer use such as Yale and UCLA in America and Helsinki in Finland (Ryanga 2002).

d) Also, Kiswahili is the only African language that has been used internationally in broadcasting and publishing. Therefore, Kiswahili is an international language.

e) Lastly, it is estimated that currently, Kiswahili has approximately 60 million speakers in East and Central Africa and in some countries in the Southern part of the Sahara desert (Msanjila 2002) and an estimated 100 million users worldwide (Katembo 2005). As such it is the most ideal language for spreading ICT in East and Central Africa.

\subsection{Kiswahili Localization Projects \\ 4.1 Microsoft Kiswahili Localization Project}

In an effort to bridge the digital divide in the developing countries, Microsoft has launched a global initiative Local Language Program (LLP) aimed at Providing desktop software and tools in different local languages (Katembo 2005). Previously, its software programs were only available in about forty (40) international languages mostly of European origin. As we have already stated, the continued use of these languages in the developing countries meant that a great number of people here who are not conversant with them were cut out of the ICT domain thus only helping to widen the 'digital divide'. Due to this fact, Microsoft, in 2004 started localization program which was aimed at providing its software programs in forty (40) local languages drawn from the developing countries. 
Kiswahili was the first language chosen in Africa for the localization project (Phombeah 2004). The Microsoft Kiswahili localization project was officially launched on 23rd April 2004. Our interview with Opiyo, the Microsoft East Africa localization manager, revealed that localization basically involved the translation of Microsoft Office and Windows into Kiswahili meaning that the future release of Microsoft programs will be available in Kiswahili. The Microsoft Kiswahili localization project was divided into two major phases - phase I and phase II.

The first phase involved the creation of a technology glossary of terms by a consortium of language and computer experts from Kenya, Uganda and Tanzania. During this phase, Microsoft East Africa was to translate about 3000 basic computer terminologies in windows and office from English to Kiswahili (see appendix). By October 2004, the glossary, containing common computer terms was complete marking the end of the first phase and laying the foundations of the second phase.

The second phase aimed at localizing 250000 windows terms and 250000 office terms in the operating system and office 2003 application. The end results of this phase was going to ensure that Kiswahili language was incorporated into the next buddle of Microsoft Windows operating system and Office 2003 thereby empowering Kiswahili speakers to access computer technology in a language they know all to well. Part of the results of the second phase was officially released on $14^{\text {th }}$ December 2005 being a Swahili version of Microsoft office 2003 application. As such users of the Kiswahili version of Microsoft Office 2003 can now convert all Microsoft Office programs like Ms Word, Ms Excel, Ms Power-point and Ms Outlook from English into Kiswahili. Meanwhile, the Kiswahili version of Microsoft windows is still being developed for a later release.

In short, the Microsoft Kiswahili Localization project is aimed at empowering the Kiswahili speakers in East Africa and beyond ICT. This definitely will go along way in bridging the digital divide in the greater East African region.

\subsection{Linux Kiswahili Localization Project}

Linux is another major computer software developer that has also been involved with the Kiswahili localization project. Like Microsoft East Africa, Linux aims at using Kiswahili as a medium of spreading computer technology in the East and Central African region. This project is known as Kilinux (klnX) Jambo open office 1.1.3 which is an open Kiswahili localization project of Linux operating systems (klnX 2004)

Linux localization project is a joint effort between the University of Dar es Salaam (UDSM) through the department of computer science and Institute of Kiswahili Research (IKR) and a Swedish IT consultancy company IT +46 . The project was funded by Swedish Development Agency (SIDA) and UDSM. The Linux Kiswahili Localization Project was in two phases.(klnX 2004). The first phase of the project involved the creation of English - Kiswahili glossary of the common computer terms (see appendix). Upon it's completion the glossary had a total of 700 terminologies.

The second phase of Kilinux Jambo Open Office 1.1.3 is also complete and available for use by Kiswahili speakers in East Africa and beyond. According to Kilinux (2004) Linux operating systems were translated into Kiswahili. Some of the localized programs include:- 
a) A Word processor called Writer which handles tasks like word processing, mail merging and spell checking.

b) A Spreadsheet program called Calc for calculating and analyzing data and can be compatible to Microsoft Excel.

c) A Drawing and Illustration program known as Draw. It is used in making web graphics like banners and logos and so it is a desktop publishing program.

d) A presentation creator called Impress for creating multimedia presentations with slide shows and animation effects. It's compatible to Microsoft power-point.

d) A data source editor which is for database management like creating tables, forms, macros and reports.

The Kilinux Jambo Open Office 1.1.3 also has software for children in Kiswahili language which is a complete Swahili adaptation of Tux - Paint, a drawing program for children (klnX 2004). This is an important program as it introduces Kiswahili - speaking children to the world of computers. Earlier, children in East Africa who had access to computers could not use them unless they knew English, something that is rare at their age.

\subsection{Kiswahili Text to Speech (TTS) Program}

This is yet another software project that involves the use of Kiswahili language in computers. The text to speech program (TTS) uses computer technology to change written text into speech when such text is feed in a computer installed with the software (Muchemi et al. 2005). This means that by using TTS technology, a computer can be able to read aloud any Kiswahili text.

The development of Kiswahili TTS software was carried out in Kenya by a team of local computer scientists and Kiswahili linguists. It involved the collection of 10558 Kiswahili sentences in order to get a large database of various Kiswahili sounds. Later these sounds were used in the programming of the TTS software. Part of the TTS programming the recording of all these sounds using a computer as they were being read out aloud by one person for voice uniformity. Kiswahili language again is the first local language in the whole of Africa to use TTS technology but there are plans to use other African languages to like Zulu of South Africa in future (Muchemi et al. 2004).

The Kiswahili TTS software has several benefits to the Kiswahili speakers in East and Central African region and beyond. The benefits include:-

a) It can be used as a Kiswahili teaching aid especially for foreigners learning Kiswahili words for the first time. Mostly, it can be useful in learning Kiswahili words pronunciations.

b) The program can also be used in aiding blind people in reading of Kiswahili texts.

c) Also TTS technology can be used in Automated Teller Machine and cell phones to read aloud Kiswahili text messages such as SMS text in cell phones and operating instructions in ATMs.

In short, Kiswahili has joined a few languages in the world that utilize the TTS technology. Examples of these other languages are like English, French, Chinese, Spanish, Hindu and Arabic (Muchemi et al.2004). 
Currently, the Kiswahili TTS is complete and can be used by Kiswahili speakers with plans underway to develop a Kiswahili Speech to Text (STT) software in future for converting Kiswahili speeches into text ${ }^{1}$. Through the Kiswahili TTS, Kiswahili speakers have been exposed further to the computer in their own language. This is a step in narrowing the 'digital divide' using a local African language.

\subsection{The Kiswahili Version of Googles Search Engine}

In October 2004, The Kiswahili version of Googles search engine was officially launched in Kenya under the . ke domain. It joined other search engines under the local domains eg South Africa (.za), England (.uk), Germany (.de) and Japan (.jp). All these local local domain googles search engines under the international Googles search engine (Khayesi 2002). The launch of a Kiswahili Googles search engine implies that Kiswahili speakers had made a huge step towards digital inclusion. The search engine is also a vital tool of storing and disseminating Kiswahili research via the internet. Already, the . ke domain have a great volume of Kiswahili materials online.

\subsection{Kiswahili E - Mail Project}

According to Khayesi (2002) a Kiswahili e - mail have been developed by 2001 Mail Africa International in collaboration with ISP Kenya. This was done by translating the e- mail operating manual from English to Kiswahili meaning that Kiswahili speakers can now access e - mail services in their very own language. This is another significant step towards providing internet services in Kiswahili language and more so helping in bridging the digital divide.

\subsection{Evaluation of the Kiswahili Localization Projects.}

The Kiswahili localization projects discussed above are quite a significant step towards digitalizing Africa. Later, plans are underway of using other popular African languages in the field of ICT. Already, these products have started rolling in the market meaning that they are getting popular with the targeted population. For example, by early January 2006, more than 700 downloads of the Microsoft Kiswahili Office 2003 had been done despite the fact that the product was only launched in mid December 2005.

Despite this, a critical examination reveals that there might be a few challenges in the implementation and eventual consumption of these products by the targeted group that comprise of Africans without any understanding of the foreign languages used to spread ICT across Africa presently. It is evident that some of the localized terms are way above the understanding of many ordinary Kiswahili speakers (see appendix). This is because they are complex and therefore only helpful to Kiswahili linguists and scholars. Such hard terminologies will thus tend to put off some of the would-be users. Also a look at the Linux and Microsoft localized terms reveals that they have different transactions for a single English term. This greatly confuses the users and it might lead to low use of the products.

Again, most Kiswahili speakers have negative attitude towards the language and they would rather use English in official matters and in new technologies like ICT. This, in the East African region where Kiswahili has its roots, is quite evident in Kenya and Uganda. However, Kiswahili is quite popular in Tanzania and the language can be quite effective in spreading computer technology to the grassroots.

${ }^{1}$ See http://www:llsti.org/demos-interactive.htm.languages.htm 
Lastly, most of the Kiswahili software are placed in the internet for downloading and eventual use by the targeted people. This might act as a hindrance in their consumption as most people in Africa have no access to computers leave alone the internet.

As such these challenges must be well addressed if the Kiswahili computer software are to be used in spreading ICT in East Africa and the rest of Africa. However, despite such drawbacks there is a lot of hope that using African languages in computers is one sure way of digitalizing Africa. The targeted population must also be sensitized on the importance of the Kiswahili software in bringing ICT closer to them in their own language.

\subsection{Conclusion}

We have argued for the use of local languages in Africa in the spread and use of ICT. This will make it possible for the ICT to reach more African population and therefore helping a lot in bridging the digital divide. It is now clear that in order for Africa and the rest of the developing world not to be left behind in the ICT sector, they need this technology in their own indigenous languages so that most of their people who do not understand foreign languages can access it without the language barrier.

One such language that has been advocated for across Africa as a suitable ICT language is Kiswahili. Kiswahili language has already started being used for spreading ICT in East and Central Africa through efforts like those of Microsoft East Africa and Linux, both being international software developers. Kiswahili is found to be a suitable language to handle this task as it's the most popular in terms of wide use not only within Africa but internationally. Thus, it's the best placed local language for ICT spread in Africa. Hence, if we are striving to create a digital Africa, Kiswahili holds the key.

\subsection{References}

Amatubi, M.N. (2002). "Globalization and the mainstreaming of Kiswahili research in the $21^{\text {st }}$ Century" Utafiti wa Kiswahili pp. $43-48$.

bridges. org. (2004). 'Bridging the digital divide' from http://www.bridges.org/digital divide (accessed December 2006)

Hoffman,D.L and T.P Novak (2000). "The growing digital divide: Implication for an open research agenda" in Understanding the digital economy: Data, tools and research. B. Kahin and E. Bryolffso (eds) Cambridge: M.T Press

Internet World Stats, (2004). "The digital divide, ICT and the 50 x 15 Initiative from http:// www.Internet coaching library/digital divide (accessed October 2006)

Katembo,I.B.(2005). "Kiswahili, the Global Economy and the African American". Seminar paper presented at the International Symposium on Kiswahili language and Globalization. University of Dar es Salaam,Tanzania ,July 4 - 7, 2005 
KlnX (2004). Jambo Open Office: A Swahili version of open office, Department of Computer Science, University of Dar es Salaam

Kamau, S.N (2005). Matumizi ya Kiswahili katika Tarakilishi, Masters Thesis (Unpublished): Kenyatta University.

Khayesi, M.K. (2002). 'Kiswahili and Information Technology (I.T): Challenges in Public University Libraries in Kenya' Kiswahili Vol 65 pp. $24-31$.

Mazrui na Mazrui. (1995). Swahili State and Society. Nairobi, East African Educational Publishers.

Mohochi, E. (2002). "Teknolojia ya Mawasiliano na nafasi ya Kiswahili Ulimwenguni in Utafiti wa Kiswahili I.K Simala (ed) Maseno: Maseno University.

Msanjila Y.P (2002). “Dhima ya Kiswahili katika karne ya 21” Kiswahili Vol 65 pp 16 - 23

Muchemi, G., Iraki, F.K et al. (2005) 'Kiswahili Interactive demo', from http://www:llsti.org/ demos-interactive.htm.languages.htm [Accessed December 2006]

Muchemi, G., Iraki, F.K et al. (2004) 'Design of Speech database for unit-selection in Kiswahili TTS', from http:www.llsti.org/pubs/Kiswahil_Speech_database.pdf [Accessed December 2006]

Mwaro, A.G. (2002). 'Mchango wa A.S.Nabhany katika Utafiti na Utandaridhi wa Istilahi za Kiswahili' Utafiti wa Kiswahili, pp 49 - 56.

Phombeah, G. (2004). 'Microsoft to launch in Kiswahili' from www //news .bbc .co.uk /2/ hi/ Africa/3816717.stm. (accessed October 2006)

Ryanga, S. (2002). 'The African Union in the Wake of Globalization: The Forgotten Language Dimension' Kiswahili Vol. 65. pp $1-15$.

Simala, I.K. (2002). Utafiti wa Kiswahili. Maseno, Maseno University.

Warschauer, M. (1999). Electronic Literacy: Language, Culture and Power in the Online Education. Mhwah, N.J: Lawrence Erlbaum Associates. 


\subsection{Appendix}

Table. 1. Some of the Linux and Microsoft Localized Terms.

\begin{tabular}{|c|c|c|}
\hline $\begin{array}{l}\text { English Computer } \\
\text { Terminologies }\end{array}$ & $\begin{array}{l}\text { Linux Kiswahili } \\
\text { Translations }\end{array}$ & $\begin{array}{l}\text { Microsoft Kiswahili } \\
\text { Translations }\end{array}$ \\
\hline access (v) & fikia & fikia \\
\hline account & akaunti & akaunti \\
\hline activate & amilisha & amilisha \\
\hline add & ongeza & ongeza \\
\hline attachment & funge & kiambatisho \\
\hline autoformat & fomati otomati & muundo oto \\
\hline bar & mwambaa & pau \\
\hline bold & koza & herufi koza \\
\hline browser & kivinjari & kisakuzi \\
\hline browse & vinjari & sakura \\
\hline button & kitufe & kitufe \\
\hline calculator & kikokotoo & kikokotoo \\
\hline click & bofya & bofya \\
\hline command & amri & amri \\
\hline computer & kompyuta & ngamizi \\
\hline create & unda & unda \\
\hline cursor & kasa & kielekezi \\
\hline cut & kata & kata \\
\hline database & hifadhidata & hazina data \\
\hline data & data & data \\
\hline delete & futa & futa \\
\hline desktop & dawati & eneo kazi \\
\hline double-click & bofyabofya & bofya maradufu \\
\hline download & pakua & pakua \\
\hline drag & kokota & buruta \\
\hline driver & dreva & kiendeshaji \\
\hline
\end{tabular}


142 Stephen Njihia Kamau

\begin{tabular}{|c|c|c|}
\hline edit (the action) & hariri & hariri \\
\hline e-mail & barua e- & barua-pepe \\
\hline Esc (escape) & epa (epuka) & epuka \\
\hline floppy disk & diski tepe & \\
\hline folder & folda & folda \\
\hline font & fonti & fonti \\
\hline format & fomati & umbiza \\
\hline hard drive - disk & diski kuu & diski kuu \\
\hline highlight & angaza & dhulisha \\
\hline icon & ikoni & Ikoni \\
\hline install & sakinisha & Sanidi \\
\hline insert & chomeka & chopeka \\
\hline internet & wavuti & tovuti \\
\hline italic & italiki & italiki \\
\hline keyboard & baobonye & kicharazio \\
\hline menu bar & mwambaa-menyu & upao menyu \\
\hline monitor (n) & monita & kiwaa \\
\hline mouse & puku & kipanya \\
\hline network & mtandao & mtandao \\
\hline password & nywila & neno la siri \\
\hline paste & bandika & bandika \\
\hline print & chapisha & chapa \\
\hline printer & printa & kichapishi \\
\hline program & programu & programu \\
\hline recycle bin & kisuduru & kijalala \\
\hline save & hifadhi & akibisha \\
\hline scroll bar & mwambaa biringiłc & pao vingirizi \\
\hline scroll & biringiza & Vingiriza \\
\hline search engine & injini tafuti & mtambo tafutizi \\
\hline search & tafuta & tafutiza \\
\hline
\end{tabular}


A Digital Africa Kiswahili Holds the Key

\begin{tabular}{|l|l|l|}
\hline single-click & bofya & bofya mara moja \\
\hline software & programu & programu za ngamizi \\
\hline spell-checker & kikagua tahajia & kikagua tahajia \\
\hline spreadsheet & lahajedwali & programu ya taarifa kazi \\
\hline template & templeti & kiolezo \\
\hline toolbar & mwambaa zana & pauzana \\
\hline virus & kirusi & kirusi \\
\hline website & tovuti & wavuti \\
\hline window & dirisha & dirisha \\
\hline wizard & sogora & kigagula \\
\hline WWW (World Wide Web) & $\begin{array}{l}\text { WWW (Wavu Wa } \\
\text { Walimwengu) }\end{array}$ & wavuti wazi wasilianishi \\
\hline
\end{tabular}

